\title{
Integrating Agent-Based Human Behavior Simulation with Building Information Modeling for Building Design
}

\author{
Jack C. P. Cheng and Vincent J. L. Gan
}

\begin{abstract}
Human behavior needs to be considered when designing buildings and infrastructures. In recent decades, building information modeling (BIM) has been increasingly adopted as a computer aided design methodology for architectural design, engineering design simulation and evaluation, and 4D constructability analysis. BIM models can be used to conduct engineering analyses while human behavior simulation using BIM models is still lacking. The research objective of this study is to connect BIM software with the human behavior simulation engine utilizing object-oriented computer programming language. A behavioral modeling engine is also developed in this study upon the agent-based modeling (ABM) approach. Finally, this paper presents a demonstrative example of four scenarios and the result proves that implementation of the occupant simulation help improve building design.
\end{abstract}

Index Terms-Agent based modeling, building information modeling, human behavior, building design, emergency simulation

\section{INTRODUCTION}

Consideration of human factors in building design includes behavior in cases of emergencies (e.g. fire and earthquake) and day-to-day operations. Due to the massive casualties and property damage caused by an emergency, most of the previous work in human behavior simulation in buildings centered on emergency situations. Nowadays, engineers have come to realize the importance of human behavior simulation in day-to-day situations since occupants make decisions day by day that influence interior facilities and systems and change the energy utilization. In addition, the building structure and internal design often affect their decision and behavior. This research stream is mainly focused on modeling building occupancy and then analyzing the impact of occupants on the building and vice versa.

In the construction industry, building information modeling (BIM) has been extensively utilized as a computer-aided design (CAD) methodology. In addition to creating digital models, BIM can store abundant building information and incorporate third party software programs (e.g. ETABS) for design analyses. The feasibility to integrate human behavior simulation with the BIM technology has been introduced in literature [1], but there is still little effort to establish such an integration. Due to the significance of human behaviors in building design and the lack of integration between human behavior simulations with BIM,

Manuscript received February 10, 2013; revised May 9, 2013.

The authors are with the Department of Civil and Environmental Engineering, The Hong Kong University of Science and Technology, Hong Kong SAR, China (e-mail: cejcheng@ust.hk). this study aims to develop a human behavior simulation engine based on agent-based technique and a reliable link between this engine and BIM software.

\section{BACKGROUND}

\section{A. Building Information Modeling}

Building information modeling is defined by the United States National BIM Standard as "a digital representation of physical and functional characteristics of a facility" [2]. "A BIM model is a shared knowledge resource for information about a facility forming a reliable basis for decisions over its life cycle, which is defined as existing from earliest conception to demolition" [2]. Application of BIM on construction management is attracting more attention because recently the design, construction, and management of building and infrastructure projects require people to work collaboratively, sustainably and cost-effectively.

Every building component is a solid object in BIM models, unlike that in the 2D drawings or 3D models in the traditional CAD tools. Apart from geometric information, a BIM model contains information about materials, vendors for specific building products, quantity, cost, schedule, etc. A BIM model can be exported and used in third party software programs to conduct structural analysis, mechanical/HVAC simulation, solar and energy analysis, and other analyses.

BIM is beneficial to developers, facility managers, architects, engineers, contractors and more importantly, the construction industry [3]. It offers a platform where a collection of project participants work together for sharing construction documents and information, improving efficiency and collaboration, and predicting and identifying potential problems. This process is known as integrated project delivery (IPD), which leads to a more reliable delivery system that maximizes the project value.

\section{B. Agent-Based Modeling}

Agent-based modeling (ABM) is a relatively new approach for modeling real world systems. Although there are various different definitions of agents, a common view of an intelligent agent is a piece of computer software that is situated, autonomous, reactive, proactive, social, and flexible [4], [5]. Each agent has attributes and behaviors controlled by decision rules, and is persistently interacting with other agents in an environment to pursue specific goals. ABM is a decentralized modeling technique which combines the computer programs in a distributed architecture as compared with the centralized modeling implemented by independent programs [6].

Since the agent paradigm was introduced, this technique 
has been successfully applied to a wide variety of domains including manufacturing operations, supply chains, transportation planning and the simulation of pedestrian movement [7], [8].

The modeling technique is becoming widespread due to the organizational structure analyzed is getting more complex while the agent paradigm for modeling and simulation of business organizations captures the nature of modeling complex systems [9]. The organizational structure becomes a large hierarchical system with many subsystems and in each level these subsystem can be decomposed into a number of independent entities. The agent paradigm divides a large problem into many autonomous components that act and react in a flexible manner in approaching their objectives [9]. Hence, ABM is well suited for modeling complex systems and is suitable for flexible management of changing organizational structures.

\section{Agent-Based Human Behavior Simulation in Buildings}

Human behavior affects other people and the environment in which one is situated. It is influenced by attitudes, culture, emotions, values A human system can be regarded as a complex system composed of a number of autonomous individuals. Each individual in a specific environment has particular attributes and follows behavioral rules. They learn to survive and make decisions in response to the changing environment where they are settled.

ABM is capable of capturing the emergent phenomena of modeling a human system. In the last few years, ABM has been applied to model human behavior simulation in buildings. Table I summarizes the past references in agent-based human behavior simulation in buildings.

One of the main research streams is to model human evacuation in case of emergency. In the simulation, an individual is simulated as an agent with specific attributes and decision rules. To identify the architectural defects which may incur inconvenience during evacuation, engineers often model the emergent behavior of a large number of human agents and analyze their evacuation pattern. Said and Kandil [10] et al. proposed an agent-based framework for modeling labor evacuation in high rise building construction sites. Pan et al. [11] defined human agents with different behavioral rules in several scenarios, and simulated and analyzed their egress patterns in a structure.

TABLE I: LiterATURES ABOUT AGENT-BASED HUMAN BEHAVIOR SIMULATION IN BUILDINGS

\begin{tabular}{lll}
\hline \hline Simulation Type & Reference & Purpose \\
\hline Emergency & {$[10][11][12]$} & Evacuation simulation \\
& {$[13][1]$} & $\begin{array}{l}\text { Modeling building occupancy } \\
\text { Maily operations }\end{array}$ \\
& {$[14]$} & $\begin{array}{l}\text { Modeling impact of occupant } \\
\text { behavior on energy use }\end{array}$ \\
\hline \hline
\end{tabular}

Another stream is to model building occupancy under day-to-day operations and analyze the building usability. Andrews et al [1] provided a framework for modeling occupancy dynamics and a case study analyzing the impact of lighting on occupants. Over the past decade, green buildings have begun to permeate the public consciousness. The increasing demand for green buildings leads to a focus on simulating occupants' impact on building energy, electricity and water consumption and the impact of the interior system (e.g. HVAC) on occupants.

The above mentioned literature shows the potential of agent-based human behavior simulation in improving building designs and in finding ways to improve building performance.

\section{PROPOSED FRAMEWORK}

Human behavior simulation in buildings helps engineers to identify design shortcomings and to improve building performance. However, human behavior simulation using BIM technology is relatively lacking, leading to difficulties of understanding the compatibility between humans and buildings. This section introduces a modeling framework to integrate an agent-based human behavior simulation engine with BIM software.

The agent-based behavioral modeling engine was developed using AnyLogic, which supports graphical modeling language and allows users to construct models with Java codes. Autodesk Revit, a widely used BIM platform, is used as the BIM software in the proposed framework. Revit provides an application programming interface (API) to facilitate data transfer and since every building component in BIM software is a solid object, Revit API supports the object-oriented programming language. The API allows software developers to add customized tool bars, functionality, and connectivity to external sources using software programs written in Visual Basic /C\#. Our modeling framework applies this methodology to transfer data from Revit to external application.

The proposed modeling framework is shown in Fig. 1. At the beginning of modeling, one should determine the structure dimensions and draw the building geometry in Revit. Users can modify the building geometry and add additional building information from time to time. The image in the top left corner presents a 3D Revit BIM model and the external tool bars.

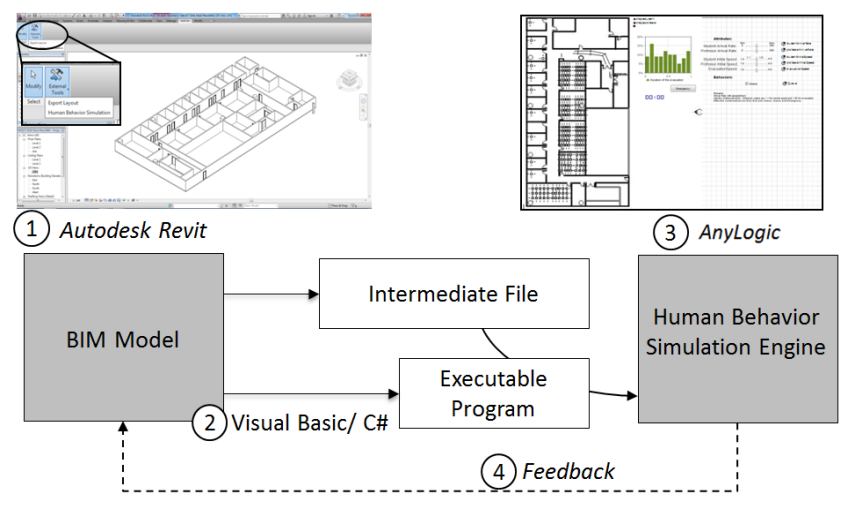

Fig. 1. Modeling framework

The second step in the modeling is to transfer the BIM model data to the behavioral modeling engine through Revit API. The customized tool bar programmed by Visual C\# will trigger two automatic processes. Firstly, the BIM model data will be exported into intermediate files and stored in a designated folder for simulation of the building geometry in the agent-based simulation engine. Secondly, the tool 
activates an external program written in Java, which will read the previous intermediate file and upload the information to the behavioral modeling engine.

The third step of the modeling framework is to define the modeling configuration in the human behavior simulation engine. As mentioned previously, the structure of an agent-based model comprises 1) a set of interacting agents with specific attributes and decision rules, and 2) the environment in which the agents are situated. Thus, the simulation engine should at least include two components: 1) an agent definition panel where users can define and adjust the human agent attributes, behavior and interaction, and 2) an environment setup panel where the building geometry can be incorporated and the structural configuration can be defined. The image in the top right corner of Fig. 1 shows an illustrative example of the simulation engine.

Modeling human behavior in emergency situation normally considers the characteristics of people and their movement. In a daily operation simulation case, human behavior becomes more complex and the definition of events is getting important. For example, employees may go to the conference room for a meeting. These types of behavior are driven by specific events controlled by a settled timetable. Hence, in the agent definition panel, the modeling parameters in Table II, Table III and Table IV can be defined and added into the engine.

TABLE II: HuMAN AGENT ATTRIBUTES

\begin{tabular}{ll}
\hline \hline Attribute Type & Attribute \\
\hline Static & name, ID number \\
& $\begin{array}{l}\text { normal speed, evacuation speed, location, } \\
\text { condition (e.g.. working or rest), arrival rate, } \\
\text { tiredness level }\end{array}$ \\
\hline \hline
\end{tabular}

TABLE III: BEHAVIORAL RULES IN EMERGENCY SIMULATION

\begin{tabular}{ll}
\hline \hline Behavior & Behavioral Rule \\
\hline IF emergency occurs; & THEN cancel all activities and set (agent type). \\
Evacuation & ELSE go on current activities; \\
& IF encountering others near the exit; \\
THeuing & ELSE evacuate following the queue direction; \\
&
\end{tabular}

TABLE IV: BEHAVIORAL RULES IN DAILY BEHAVIOR SIMULATION

\begin{tabular}{ll}
\hline \hline Behavior & Behavioral Rule \\
\hline $\begin{array}{l}\text { Teaching/ attending } \\
\text { a course }\end{array}$ & $\begin{array}{l}\text { IF course is started; THEN go to classroom; } \\
\text { IF course is completed; THEN go to } \\
\text { office/home; }\end{array}$ \\
Taking a break/ \\
going to washroom
\end{tabular}$\quad \begin{aligned} & \text { THEN take a break (or go to washroom and } \\
& \text { delay for xx minutes); } \\
& \text { IF work time }<\text { xx hours and other activities are } \\
& \text { Forking }\end{aligned}$

In the environment setup panel, users should define the structural configuration such as walls, obstacles, entrance, exit, safe egress, places where agents often stay. The human agents defined in the agent setup panel can recognize the structure and move within the defined environment.

Once the structural configuration and agents have been defined, users can start the simulation and analyze the behavior of various human agents. The simulation engine performs as a decision support tool, returning feedback information to the users. The modeling results help the architects and engineers to identify any plan shortcomings and find a way for plan improvement.

The proposed modeling framework can address the gap between the human behavior simulation engine and BIM models. In addition, more attributes and behavior rules can be defined and added to the simulation engine for modeling complex human behavior in buildings. Section IV provides a demonstrative example to illustrate the operation of the modeling framework.

\section{DEMONSTRATIVE EXAMPLE}

\section{A. Scenario Settings}

The environment chosen is a section of the academic building at the Hong Kong University of Science and Technology, which comprises 14 offices, 5 classrooms, 1 administration center, a normal entrance and exit, and an emergency exit. After construction of the BIM model in Revit, the layout is exported through the API and C\# application for human behavior simulation. Fig. 2 shows the 3D BIM model of the academic building in Revit. In the human behavior simulation system, users should define the normal entrance and exit, emergency exit, and walls. Fig. 3 is a snapshot of the academic building during simulation.

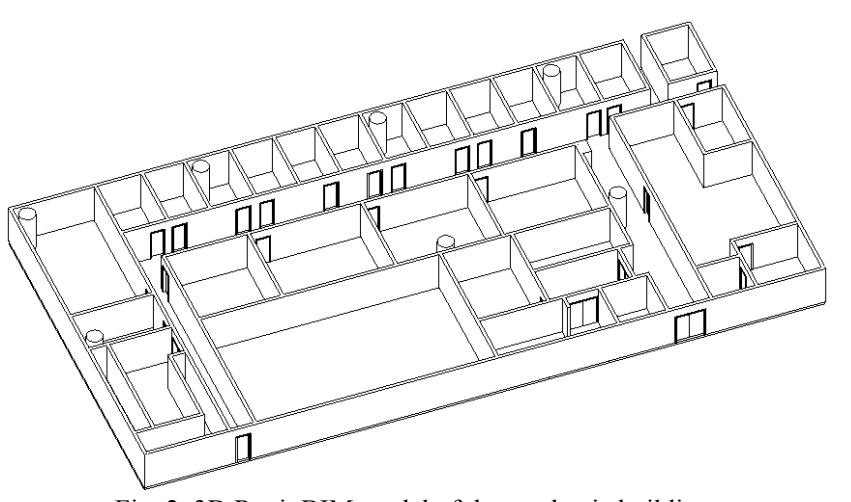

Fig. 2. 3D Revit BIM model of the academic building.

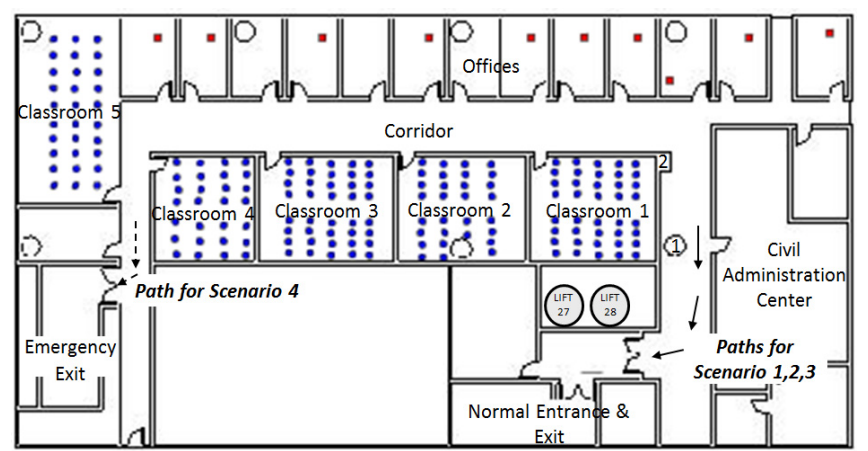

Fig. 3. A snapshot of the academic building before emergency simulation. 
TABLE VI: EVACUATION INTERVALS AND EGRESS PATTERNS OF DIFFERENT SCENARIOS

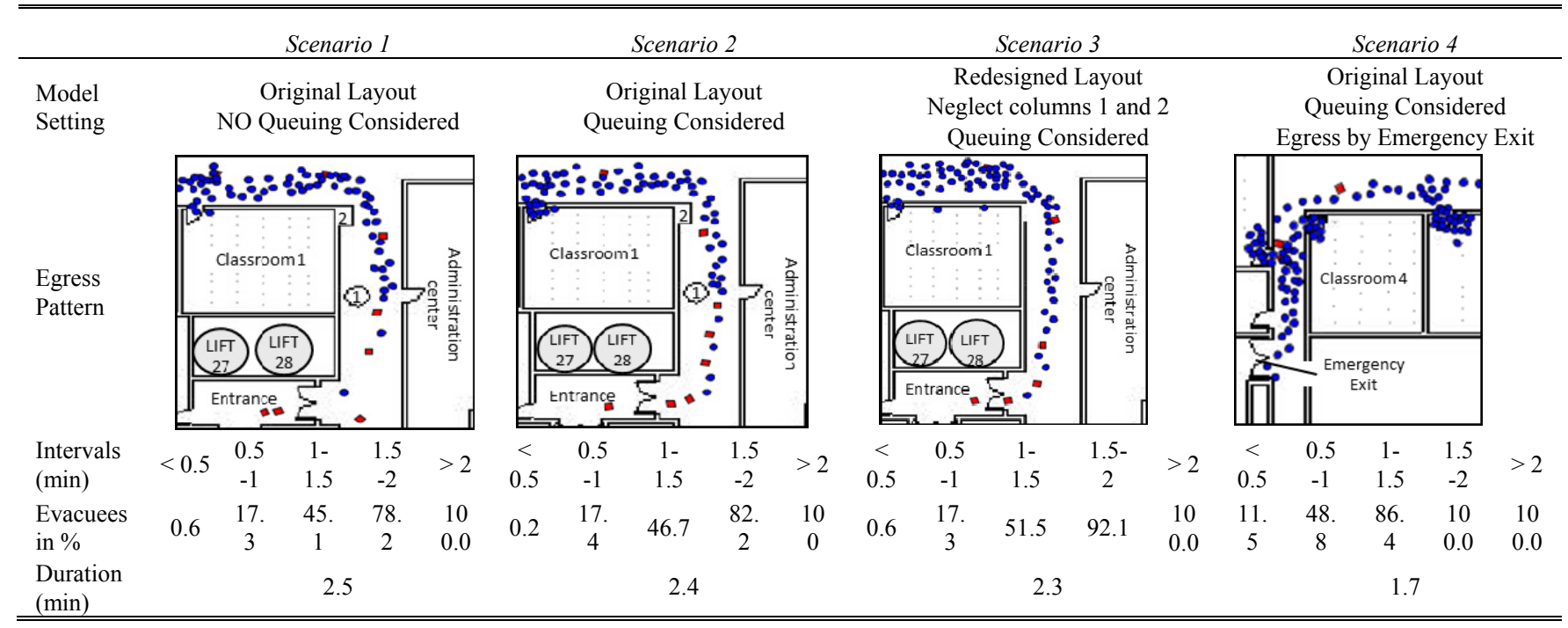

Two types of occupants are defined in the demonstrative example: (1) 10 professor agents (the rectangles in Fig. 3) and (2) 170 student agents (circles). In this example, we only model and analyze the human evacuation behavior in case of emergency. Hence, the behaviors in daily situation such as teaching and attending courses are not herein shown.

First, agents will enter the building through the entrance with a normal speed of $1.1 \mathrm{~m} / \mathrm{s}$. The professor agents will go to different offices while the student agents will go to different classrooms (as shown in Fig. 3). Then, the agents are working in the locations where they are settled. When emergency occurs, all the agents will evacuate with an evacuation speed of $1.4 \mathrm{~m} / \mathrm{s}$ from their current locations to the exit. We test four scenarios in the example and in each scenario agents will evacuate through only one exit. In scenarios 1, 2 and 3, the normal exit is used while scenario 4 uses the emergency exit.

Scenario 1 is the original layout without considering queuing while scenario 2 considers the queuing capacity. In scenario 3 , the queuing capacity is also considered but columns 1 and 2 (marked in Fig. 3) opposite to the administration center have been neglected. In previous scenarios, the student and professor agents will escape from the academic building through the normal exit. Scenario 4 considers the emergency exit and all agents will evacuate through this safe egress.

TABLE V: AgENT DEFINITION IN DEMONSTRATIVE EXAMPLE

\begin{tabular}{llc}
\hline \hline Agent Type & Attributes & Behavioral Rule \\
\hline $\begin{array}{l}\text { Professor } \\
\text { OR }\end{array}$ & Normal Speed, & FOREACH Professor/Student DO \\
Etudent & IF wocuation Speed & activities are FALSE; \\
& THEN stay in the offices /classroom \\
& s; & \\
& ELSEIF work time $>$ xx hours; \\
& THEN go home; \\
& ELSEIF emergency occurs; \\
& THEN cancel all activities and set \\
& (agent type).arrival rate $=0$ and \\
& escape; \\
& END \\
\hline \hline
\end{tabular}

Table $\mathrm{V}$ summarizes the agent attributes and behavioral rules in the example. Table VI concludes the modeling configurations of the four scenarios, the snapshots closed to the exits during simulation, and the simulation results.

\section{B. Results and Discussion}

Each scenario was tested 10 times and the average values were counted for comparison and analysis. In agent-based modeling and simulation, it is usual to analyze the emergent phenomena of a set of agents rather than individual behavior. Hence, we shift attention to a group of occupants and analyze their egress pattern.

Comparing the egress pattern of scenario 1 and 2 , the first evacuation pattern is worse due to the lack of queuing near the exit. In scenario 1 the professor and student agents scramble towards the normal exit while in scenario 2 the agents egress in a good order when they are closed to the normal exit. A slight difference between the egress pattern of scenario 2 and 3 is that evacuees have more space to escape when they pass the corridor adjacent to the administration center. This leads to a reduction of 0.1 minutes ( 6 seconds) in the evacuation duration. In scenario 4 , the occupants inside the building will evacuate through the emergency exit. Because the emergency exit is close to the classroom, more student agents can leave the academic building in a shorter time. The evacuation duration of scenario 4 is 1.7 minutes, which is a big improvement among the four scenarios.

The lines in Fig. 4 present the percentage of successful evacuees against the evacuation intervals. Scenario 1 has the lowest value. Scenario 2 has similar trend but its values during 1 to 1.5 , and 1.5 to 2 minutes are larger than that of scenario 1. This means that people will take less time to evacuate once they recognize the importance of queuing.

The values of scenario 3 between 1 and 2 minutes are larger than those of scenario 2 (by roughly $15 \%$ in total). The discrepancy between the scenario 2 and 3 indicates that removing the columns opposite to administration center allow evacuees to escape earlier and improve the evacuation efficiency. 


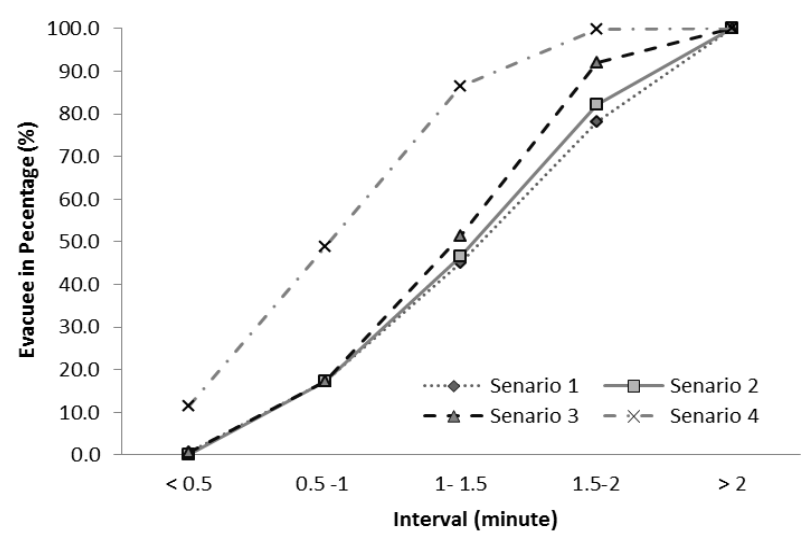

Fig. 4. Evacuees in percentage against the evacuation intervals.

The dot-dash line Fig. 4 presents the result of scenario 4 . $11.5 \%$ of the occupants escape from the academic building in less than 0.5 minutes and approximately half of the occupants leave the building between 0.5 and $1 \mathrm{~min}$. This is a big improvement as compared with the previous scenarios.

It is clear that the last scenario has the highest evacuation efficiency and a safer design is to construct an emergency exit for evacuation. On the other hand, proper evacuation education and management should be provided for the occupants such that the evacuees will not panic when emergency occurs

In the illustrative example, agents are allowed to evacuate by only one exit. In reality, however, evacuees may escape through both normal exit and emergency exit, depending on the distance between current locations and the exits. Thus, the evacuation duration for real condition may be even shorter than scenario 4.

\section{CONCLUSION}

This paper proposes a system framework to integrate human behavior simulation with BIM models for simulation of human behavior in buildings in both emergency and daily operation situations. The demonstrative example presented in part IV shows the operation of the modeling framework. Incorporation of human behavior simulation in BIM software facilitates building geometry creation in the simulation engine and helps engineers to improve building designs.

The proposed modeling framework is still in a prototype stage. The simulation engine will be enhanced by implemeting the cellular automata manoeuvring module as mentioned in [10]. In addition, the simulation engine will be constructed as an independent program and embedded in the BIM software. Moreover, more behaviral rules will be identified and added into the simulation engine for modeling complex human behavior in buildings.

\section{REFERENCES}

[1] C. J. Andrews et al., "Designing buildings for real occupants: An agent-based approach," Systems, Man and Cybernetics, Part A.
Systems and Humans, IEEE Transactions, vol. 41, pp. 1077-1091, NOV 2011.

[2] National Building Information Model Standard Project Committee, Frequently Asked Questions About the National BIM Standard-United States ${ }^{\mathrm{TM}}$ [Online]. Available: http://www.buildingsmartalliance.org/index.php/nbims/faq/ (Accessed in $10 \mathrm{Jan}, 2013)$.

[3] BIM handbook: A Guide to Building Information Modeling for Owners, Managers, Architects, Engineers, Contractors, and Fabricators, John Wiley \& Sons Ltd., Hoboken, NJ, 2008.

[4] L. Padgham and M. Winikoff, Developing Intelligent Agent Systems, John Wiley \& Sons Ltd., England, 2004, pp.1 - 6.

[5] C. M. Macal and M. J. North, "Tutorial on agent-based modeling and simulation part 2: How to model with agents," in Proc. 2006 Winter Simulation Conference, Argonne, IL 60439, U.S.A., Dec. 2006.

[6] Michael J. North and C. M. Macal., Managing business complexity: discovering strategic solutions with agent-based modeling and simulation. Oxford university press., USA, 2007.

[7] Z. Ren and C. J. Anumba, "Multi-agent systems in construction-state of the art and prospects," Automation in Construction, vol. 13, pp. 421-434, May 2004.

[8] F. T. S. Chan and H. K. Chan, "The future trend on system-wide modelling in supply chain studies," The International Journal of Advanced Manufacturing Technology, vol. 25, pp. 820-832, April 2005.

[9] N. R. Jennings, "An agent-based approach for building complex software systems," Communications of the ACM, vol. 44, pp. 35 - 41, April 2001.

[10] H. Said, et al., "Agent-based simulation of labour emergency evacuation in high-rise building construction sites," presented at the Construction Research Congress, West Lafayette, Indiana, United States, May 2012

[11] X. Pan, et al., "Human and social behavior in computational modeling and analysis of egress," Automation in Construction, vol. 15, pp. 448-461, July 2006.

[12] N. Pelechano and A. Malkawi., "Evacuation simulation models: Challenges in modeling high rise building evacuation with cellular automata approaches," Automation in Construction, vol. 17, pp. 337-385, May 2008

[13] C. Liao and P. Barooah., "A novel stochastic agent-based model of building occupancy," presented at the American Control Conference, on O'Farrell Street, San Francisco, CA, USA, June 2011.

[14] Elie Azar and C. C. Menassa., "Agent-based modeling of occupants' impact on energy use in commercial buildings," Computing in Civil Engineering, vol. 26(4), pp. 506-518, June 2011.

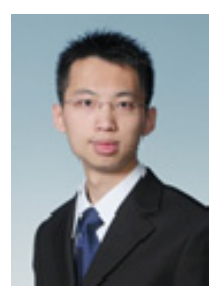

Jack C. P. Cheng is an assistant professor in Department of Civil and Environmental Engineering at the Hong Kong University of Science and Technology. He received his Bachelor and Master of Philosophy degrees at the Hong Kong University of Science and Technology, Hong Kong. He then received his Doctor of Philosophy degree at Stanford University, USA. His research areas include building information modeling (BIM), knowledge management, data retrieval and mining, green building, sustainable construction and built environment, and service computing for construction management.

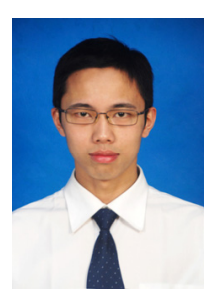

Vincent J. L. Gan is a PhD student from the Hong Kong University of Science and Technology. He holds dual degree with first bachelor degree in construction management from China University of Geoscience and second bachelor degree in architecture from Huazhong University of Science and Technology. He obtained his MSc from the HKUST and his early work involved computer simulation and analysis of cementitious materials. His recent research focuses on agent-based modeling and simulation, green building construction, life cycle assessment of construction material. 